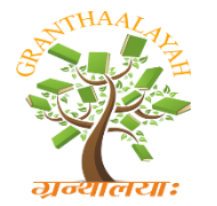
INTERNATIONAL JOURNAL OF RESEARCH
GRANTHAALAYAH
A knowledge Repository

Management

\title{
ANALYZING THE BEHAVIOURAL PATTERN OF INDIAN RAILWAYS PASSENGERS WITH REGARDS TO DISPOSAL OF WASTE
}

\author{
Abhishek Gawande *1 \\ ${ }^{* 1}$ Indian Institute of Forest Management, Bhopal, India
}

\begin{abstract}
Indian Railways is the biggest public-sector enterprise in India and connects the entire country. The rail network is spread across the lengths \& breadths of the country and one of the biggest worries is the enormous amount of solid waste generated each day by the passengers during the rail journey. It is unfortunate to note that such a huge public transport system does not have a proper waste management system in place. Due to inefficient handling of the waste, there has been a severe impact on the surrounding environment across the rail network. It is in this regards a study was undertaken to enlist the problems related with the disposal of waste during the rail journey and subsequently propose solutions for effective waste management system. The study enumerates the type of waste and the perception of passengers with regards to disposal of waste during rail journey. In order to perform this study, a detailed passenger survey was carried out with the help of structured questionnaire and personal interviews. The survey focused on all kinds of passengers whether travelling by Air conditioned, Sleeper or General class. The data gathered from the study revealed that there are several lacunas in the existing waste management system of Indian Railways. Therefore, a solution of comprehensive waste collection system is proposed primarily in all coaches to ensure proper segregation and disposal of waste, thereby minimizing impacts on surrounding ecosystem. The collected waste can be reused, recycled and thus result in revenue generation for Indian railways. This study could be of great importance to the wider spectrum of researchers, analysts and students for further studies as this area of research has not been studied adequately in the past.
\end{abstract}

Keywords: Waste Management; Indian Railways; Solid Waste; Passengers' Behavior; Clean; Green Railways.

Cite This Article: Abhishek Gawande. (2018). "ANALYZING THE BEHAVIOURAL PATTERN OF INDIAN RAILWAYS PASSENGERS WITH REGARDS TO DISPOSAL OF WASTE." International Journal of Research - Granthaalayah, 6(4), 138-143. https://doi.org/10.29121/granthaalayah.v6.i4.2018.1625.

\section{Introduction}

The Indian Railways (IR) is the third largest rail network in the world with 66,000 route kilometers covering more than 8000 stations (Kumar, 2017). The passenger base of IR grew exponentially 
from 3.6 billion to 8.2 billion in last four decades at an average rate of $4 \%$ per annum. (MOHIT SHARMA, 2016) It is among one of the largest and oldest systems in the world and rightly called as the "lifeline of the nation". IR is also one of the biggest state-owned enterprise in the country whose contribution towards country's GDP is about $1 \%$ (Prasad and Shekhar, 2010). While the Railways is one of the most economical, convenient and environment friendly modes of transport, one of the growing challenge is that of waste management. Around 23 million passengers travel by IR per day (IR, 2015) which results in an enormous amount of solid waste generation. It is estimated that solid waste generated at major railway stations across the country is nearly 670 tonnes per day (TPD). Out of this, major contribution is of plastic waste amounting to roughly 340 TPD. (MOHIT SHARMA, 2016) . A recent Comptroller and Auditor General of India (CAG) report observed, "Passenger amenities like toilets and urinals at stations are not commensurate with the quantum of passengers using them and are poorly maintained at many stations, thereby straining existing facilities and hampering cleanliness efforts with passengers overcrowding the station premises. This is further complicated by the failure to prevent unauthorized persons from entering station premises." [CAG, 2007]. A similar problem is that of people residing near the railway tracks and stations, without access to toilet facilities, using tracks for open defecation. Stagnation of waste on tracks is common near stations and railway tracks (Raghuram, 2008). In such cases, it presents a very poor impression about the country's image among foreign tourists, though we Indians become habitual of this unhygienic practice. Apart from the poor hygiene, this causes discomfort to the passenger's onboard trains, when they stop near the stations. It also makes it difficult for the railway staff to work on or near the tracks. This becomes even more important as our Prime Minister Mr. Narendra Modi is taking all pains in convincing people of the country to adopt cleanliness and hygiene in all walks of life.

A significant amount of waste is generated daily from the running trains, the data of which is not available in reliable sources. Most of the trains lack appropriate facilities for disposal of waste. A large number of existing dustbins inside trains lack polybags and are of less capacity as compared to the size of passengers. Secondly, there is shortfall of manpower to handle the dustbins.

A random survey of four express trains was conducted by IIM Ahmedabad researchers at the Surat railway station in Gujarat to get an idea of the nature and amount of solid waste generated per train per day. Managers of the pantry car were asked about the number of meals, coffee/tea cups, meal containers and mineral water bottles they sell. It was assumed that after consumption of food, the meal containers, coffee/tea cups and mineral water bottles would be thrown away as waste. Thus, by counting the number of items sold per day the amount of waste generated was calculated. Assuming that these disposable items are thrown out of the train after consumption, it was estimated that each train generates 1,100 paper plates and containers, 1,750 paper cups and 800 plastic items (pouches and bottles) per day. These figures would assume alarming proportions when disposable items sold by other vendors as also the total number of trains plying per day in the country are considered. (Kota Sridhar, n.d.)

Table 1: Pantry Car Disposables

\begin{tabular}{|l|l|}
\hline Type of Solid waste & Number \\
\hline
\end{tabular}




\begin{tabular}{|l|l|}
\hline Paper containers (meals) & 700 \\
\hline Plastic water pouches & 700 \\
\hline Paper cups (coffee/tea) & 1750 \\
\hline Plastic bottles (mineral water) & 100 \\
\hline Paper plates / containers (tiffin) & 400 \\
\hline
\end{tabular}

There are many issues related to waste generation and disposal at railway stations like lack of separate dustbins kept for degradable and non-degradable waste at railway stations; the solid waste at the first collection point is not segregated. The collected waste from the formal system finally goes to the municipal landfill for disposal. Further, the Railway Administration frequently resorts to improper disposal of waste by burning, dumping into adjacent canal, low lying areas, and near the track, causing environmental pollution. Dustbins most of the times are either without lids or overflowing. Plastic wastes generated from the Railway stations are not collected, segregated, transported, treated, reused and disposed properly. It is commonly observed that though garbage disposal system is in place, the same is not effective enough due to lack of monitoring to ensure compliance of statutory obligations and provisions of contracts for proper disposal of garbage, deficiencies in infrastructure like adequate provision of vats, dust bins etc. There is often lack of modern and mechanized approach towards station cleanliness at small stations. Railway stations lack the infrastructure to recycle. No separate Waste Management Cell exists to look after issues relating to solid and plastic waste management and there seems no planning in this regard.

Majority of the solid waste generated in India is directly disposed of on the land in an unsatisfactory manner. Therefore, the present study aims to determine the perception of relevant stakeholders with regards to waste which is generated during the railway journey.

\section{Methodology}

The present research work is a kind of exploratory and preliminary study which enlists the problems associated with waste management during the railway journey. The study is combination of primary and secondary data. The primary data is collected with the help of personal interviews and questionnaires, whereas the secondary data is collected from research papers, journals and articles.

The qualitative data has been collected with the help of following questionnaire:

Question 1: Which class do you often travel by in Indian Railways?

Question 2: Does Indian Railways has a proper waste management system?

Question 3: Are you aware of the dustbins in trains?

Question 4: What are the types of waste you generate during the rail journey?

Question 5: Where do you dispose the generated waste during rail journey?

Question 6: Do you think that the surrounding environment across the railway tracks is getting degraded by the waste thrown by us during the railway journey?

Question 7: What measures should be taken to improve the waste management inside railway coaches?

Question 8: What do you think is a feasible solution for effectively managing the waste generated during the railway journey. 


\section{Findings}

The data was gathered from 50 respondents by filling up the structured questionnaire. The analysis of the gathered data revealed that around $78 \%$ of the respondents responded that Indian Railways does not have a proper waste management system in place. Interestingly, $20 \%$ of the respondents reported that they are not even aware of the dustbins in trains. Almost $88 \%$ of the respondents reported that the major type of waste generated during the railway journey is that of plastic, may it be in the form of plastic bottles, polythene bags or wrappers. As many as $14 \%$ reported that they simply throw away the waste from window. Almost $66 \%$ of the respondent's said that the surrounding environment across railway tracks is getting degraded by the waste thrown by passengers during the railway journey. Almost $80 \%$ of the respondents revealed that there is a need for better provisioning of dustbins within trains.

After doing the content analysis, it has been tried to assess the perception of the passengers with regards to disposal of waste during the railway journey. Several recommendations were made based on the outcome of the study as follows:

- The waste from the garbage bins placed below the wash basin should be cleared regularly at major stations.

- Currently there are only two garbage bins in a coach which is inefficient to hold the garbage of 72 odd passengers. It is recommended to increase the number of garbage bins within coaches by keeping common dustbins across coaches at a distance of some seats.

- Keeping disposable bags in different colors for collecting the dry waste.

- Timely schedule set inside the train for collection of waste.

- Place boards and attractive slogans indicating not to throw any waste through window and doors of coaches.

- Most of the passengers especially in general class don't know that a dustbin exists under wash basin. So, IR can advertise about the use of dustbins by putting up instructions throughout the bogie.

- To suggest the sweeper to segregate the different type of waste during collection.

- Incentivizing the plastic waste collection system. Passengers should be rewarded if they collect and dispose plastic bottles and polythene bags at right place.

\section{Discussions}

The problem of waste generated inside the running train and around the railway track, has become a growing concern over the years. The $1,15,000 \mathrm{Km}$ area around the railway track in India is the biggest source of waste generation which has never been cleaned. It is imperative that the railways draw up an efficient waste management system. It simply cannot continue to pollute the entire rail network spread across the length and breadth of the country, contaminating land and soil, and polluting waterbodies. The efficient waste management system inside railways would not only make IR cleaner but also the surrounding environment greener.

General cleanliness and sanitation level in India is a matter of concern (Bhatia, 2013). India can be positioned on the world tourism map only after hygiene factors during travel are improved (Chaudhary, 2000). It is noteworthy to note that the country's Prime Minister Narendra Modi has directly linked the Clean India movement with the economic health of country. Clean India can 
bring in more tourists, thereby increasing the revenue. He has appealed to the people to devote 100 hours per year to cleanliness (Nayak, 2015). The campaign of Swachh Bharat (Clean India) launched by Government of India is aimed to accomplish various goals and fulfill the vision and mission of "Clean India" by Oct 2, 2019, which is 150th birth anniversary of Nation's father Mahatama Gandhi. Inculcating healthy sanitation practices by bringing behavioral changes in people, whether at home or during travelling is one of the main objectives of Clean India campaign (Gore and Annachhatra, 2018).

Cleanliness on tracks, washrooms, platforms, near waiting rooms and seating chairs were found as the main concerns of Indian railway passengers as revealed through a survey among 1248 passengers using exploratory factor analysis at Allahabad junction of Uttar Pradesh, India (Geetika et al, 2016). In another survey conducted among 700 passengers of IR of all travel classes (AC, $2^{\text {nd }}$ sleeper) by executives of IIM Lucknow, it was revealed that cleanliness of toilets and platforms was among top two deficiencies of IR. But at the same time, it was also a matter of satisfaction (from hygiene point of view) that $64 \%$ of passengers surveyed confirmed that they have seen service improvements in IR during last five years (Dube et al 2012).

In UK the waste generated by the public modes of transports (railways and airways) is managed very efficiently and effectively with strict clear defined rules and legislations being present to strategically handle the waste in public vehicles. In UK third party handle the contract of waste management in different bus, rail and airports along with receiving a recycling fee. Whereas, the existence of waste management in India in context of railways are still scant. (De, 2015) Similar models need to be replicated across public transport systems in India to solve the problem of waste management.

\section{Conclusions}

The problem of waste generated inside the running train and around the railway tracks is growing day by day. The problem has taken its peak since the time plastic bottles and polythene is introduced in railway. The waste generated from the running train is lacking proper collection, segregation and transportation issue. Thus, Proper management of the generated waste requires the construction and installation of essential facilities based on a suitable management plan. From the study the main problems with regards to Indian Railways waste management system can be identified. This would help the various stakeholders to take corrective measures and ensure efficient waste management process which would help in making the Indian Railways cleaner and greener.

\section{Acknowledgements}

I have tried my best to present this information which can be comprehended by wider spectrum of researchers, analysts and students for further studies. I am thankful to all the teachers and mentors who helped me directly or indirectly in framing the study. I am grateful to Dr. Pradeep Chaudhary, Professor at Indian Institute of Forest Management, Bhopal for his immense support and guidance during the course of study. I am also thankful to all the respondents who supported whole heartedly in filling up the questionnaire. 


\section{References}

[1] De, D. (2015). WASTE MANAGEMENT IN THE PUBLIC TRANSPORT SYSTEMS IN INDIA, CHINA AND THE UK A COMPARATIVE ANALYSIS.

[2] Kota Sridhar, J. C. (n.d.). http://www.downtoearth.org.in/coverage/managing-railway-waste12913.

[3] MOHIT SHARMA, K. N. (2016). Decentralised Waste Management in Indian Railways. CEEW.

[4] Bhatia A (2013): SWOT analysis of Indian tourism industry. International Journal of Application or Innovation in Engineering \& Management. 2(12): 44-49.

[5] CAG, 2007. 'Cleanliness and Sanitation on Indian Railways.' Chapter 2, CAG Report No 6 of 2007

[6] Chaudhary M (2000): India's image as a tourist destination - a perspective of foreign tourists. Tourism Management. 21: 293-297.

[7] Dube K, Mehta K and Tandon A (2012): Passenger satisfaction survey report and benchmarking of performance standards. A report by Indian Railways Institute of Transport Management, Lucknow.

[8] Geetika, Ghosh P, Ojha M K and Kumar S (2016): Journey towards world class stations: An assessment of plarform amenities at Allahabad junction. Journal of Public Transportation. 19(1): 68-83

[9] Gore M and Annachhatra M (2018): Swachha Bharat Abhiyan (Clean India campaign): A step towards social accountability. European Journal of Multidisciplinary Studies. 7(2): 60-69.

[10] Kumar R (2017): Developing a stakeholder communication strategy: The case of Indian Railways and Swachh campaign. In Technological and Managerial Strategies for Next Generation Transformation edited by Tushar Kanti, J.N. Giri and Harish Bhatia Published by Bloomsbury Publishing India Pvt. Ltd. DDA Complex LSC, Building No. 4, 2nd Floor Pocket 6 \& 7, Sector C Vasant Kunj, New Delhi 110070.

[11] Nayak A (2015): Clean India. Journal of Geoscience \& Environment protection. 3: 133-139.

*Corresponding author.

E-mail address: gawandeabhishek4@gmail.com / argawande19@ iifm.ac.in 